\title{
SWOT Analysis of Forest Carbon-Sink Market Transaction in China
}

\author{
YangYing \\ North-east Agricultural Univercity, \\ Harbin 150036, China ; \\ South China Agricultural Univercity, \\ Guangzhou,510635,China \\ yangying120909@163.com
}

\author{
$\mathrm{JiaLi}^{\star}$ \\ North-east Agricultural Univercity, \\ Harbin 150036, China \\ ^jiali0451@126.com
}

\begin{abstract}
Recently, abnormal changes of global climate, represented by earth warming, has become a common threat and challenge faced by the world, and has directly affectted the existence of the human society and its sustainable development. Kyoto Protocol allowed developed countries to provide developing countries capital and technology, in order to conduct forestation and reforestation carbon-sink program, utilize the carbon amount generated by the program to counteract emission conduct target in their countries. Therefore, forest carbon-sink transaction turned into an indirect emission reduction pattern that is widely practiced by various countries in the world. Now China doesn't have to undertake the compelling emission reduction duty, but along with the increasingly deep negotiation of the international climate, the reduction pressure becomes heavier and heavier. Therefore, developing the forest carbon-sink market transaction not only is beneficial to raise money, which is needed for forestation and increase the percentage of forest cover, but also can help to relieve the emission reduction pressure confronted by China. It has strategic significance to the sustainable development of the Chinese economy. This article discusses the theory basis to conduct forest carbon-sink market transaction, using SWOT analysis method to theoretically analyze the superiority, weakness, opportunity and challenge of the development of forest carbon-sink market transaction in China. At last, It provides some relevant countermeasures and suggestions.
\end{abstract}

Key Words-Forest Carbon-Sink; Market Transaction; SWOT

I. USING SWOT ANALYSIS TO ANALYZE THE FEASIBILITY OF THE ESTABLISHMENT OF THE FOREST CARBON-SINK MARKET TRANSACTION

SWOT analysis is a common strategic thinking implement, and is widely applied during the strategy development process of enterprise and industry[1]. Currently, the government of China is facing the double pressure between $\mathrm{CO} 2$ emission reduction in the international community and rapid growth of the domestic economy, and choosing a CO2 emission reduction way that is suitable for China's actual condition is the strategic choice to achieve the sustainable development of Chinese economy. Forest carbon-sink transaction is an indirect emission reduction pattern that is widely practiced by countries in the world. China also took part in all kinds of forestation programs, however, the CERs generated from the domestic CDM programs can hardly be priced and traded through market mechanism and hold the initiative of the transaction because China haven't established its own carbon trade market, they can only be decided by the negotiation and consult between the program participants. Therefore, the government of China should deepen the understanding of the strategic position of forest carbon-sink from higher level and build the domestic forest carbon-sink market.

The author hold the opinion that the SWOT analysis not only can apply during the strategic management process of private department, but also can be used as a reference along with the decision-making process that the government built the forest carbon-sink trade market. In fact, using SWOT analysis during the strategic decision-making of the establishment of forest carbon-sink trade market by the government is to regard the market as a system, synthesize and summarize the involved content in all rounds and respectively research the four factors - superiority, weakness, opportunity and challenge, which are confronted by the establishment of the forest carbon-sink trade market.In this way, we can have a sober awareness about the current situation of the forest carbon-sink trade market in China, highlight the importance of the development of the forest carbon-sink trade market to the sustainable development of Chinese economy.

\section{EXTERNAL FACTORS ANALYSIS}

\section{A Opportunity Analysis}

1) The high attention and policy support from the government to the forest carbon-sink

The Kyoto Protocol was checked examined and approved by the government of China in Aug, 2002, and then the National Climate Change Program was announced on Jun $4^{\text {th }}$, 2007. On Nov $25^{\text {th }}$, the routine conference of the State Council made the decision that the GDP and $\mathrm{CO} 2$ emission ratio in 2020 will be $40 \%-50 \%$ less than the number in 2005, and it was set as the restrained target into the long-term project of the national economy and social development, and established the relevant vis-à-vis, monitor and assess methods. In Janurary, 2010, the first carbon-sink operation office of China was set in Beijing; in Sep, public-raised fund-The Green Carbon-Sink Foundation of China, which was The Green Carbon Foundation in the past, 
was founded; in October, forestry carbon-sink measure and detection center of State Forestry Bureau was set. The confirmation of this series of strategic objectives and measurements provided a favorable policy condition and development opportunity to forest carbon-sink.

2) Lesson from the experience of the International forest carbon-sink transaction

The forest carbon-sink market was generated and developed on the basis of the relevant legal provision of the Kyoto Protocol. Nowadays, there are mainly two CO2 compelling emission reduction markets which are respectively represented by European Union and the United States, and they all have abundant transaction experience. Take the forest carbon-sink transaction in the U.S. as an example, the government are mainly in charge to establish the transaction rule and implement monitoring and administration, however, specific matters such as transaction price depend more on the market itself. Meanwhile, in order to encourage the development of the forest carbon-sink transaction market, the government on one hand forced the distribution of the $\mathrm{CO} 2$ emission index, on the other hand, conducted the property tax relief policy[2]. The practical experience from American forest carbon-sink has great significance to the establishment of forest carbon-sink transaction market in our country.

3) The improvement of enterprise and citizens' environmental awareness and enhancement of sense of social responsibility.

Along with the increasingly fierce problem of climate change and the deepening of the energy saving and emission reduction awareness, more and more individuals and enterprises stat to buy carbon offset to counteract their carbon emission. Under the circumstance that China had no compelling $\mathrm{CO} 2$ emission limit yet, it is mainly rooted from individuals and enterprises' social responsibility to buy carbon offset. Forest carbon-sink transaction regarded the ecological value of the forest as a kind of commodity to trade around the world for the first time, which indicated that people's ecological awareness are gradually strengthening, and the operation concept of the forest resources changed from economy first to ecology first.

\section{B Threat analysis}

1) The uncertainty of forest carbon-sink transaction in post-Kyoto era

The essence of the forest carbon-sink transaction in Kyoto rule is a kind of transaction that is driven by policy, and is generated on the basis of the low cost emission reduction measure seek by developed countries. Supply and demand relation is the prerequisite of the generation of the market, and if there is no compelling rules, it is impossible for countries and enterprises to reduce the $\mathrm{CO} 2$ emission on their own. As a result, the demand of carbon credit can not be produced and the forest carbon-sink transaction market can not continue to operate. At present, the emission reduction scheme concerning the first period of Kyoto Protocol has not reached a law-restrained pact on the international society, the situation of climate politics is complicated and confusing. Therefore, the uncertainty of emission reduction policy makes both parties of the transaction undertake great risk, and has great disadvantages to the development of the forest carbon-sink transaction market [3].

2) Information asymmetry hinders the father development forest carbon-sink transaction

Forest carbon-sink transaction can involve all kinds of risks[4]. Information symmetry is the main measure to coordinate the supply and demand of the market. Besides the symmetry of the market demand information, it contains the symmetry of some basic information and knowledge. Now, the international forest carbon-sink transaction market has just emerged, popularizing rate of the forest carbon-sink knowledge is relatively low among the domestic transaction parts, and the domestic transaction participants are short of basic information and technology to develop forest carbon-sink, thus they can not fully understand the demand of the international forestry carbon-sink market. This situation has already impeded the further development of the domestic carbon-sink market and resulted in two extreme phenomenons, on the one hand, the unwillingness to take part in the forest carbon-sink transaction as they are unfamiliar with the related process. On the other hand, due to the misguidance of some material, they aimlessly participate the construction of the carbon-sink forest, therefore lead to the failure of the identification and thare are unable to join the transaction.

\section{INTERNAL FACTORS ANALYSIS}

\section{A Superiority analysis}

1) Stable social system has benefit to reduce the transaction cost

During the more than 30 years after reform and opening-up, the economy of Chinese society has developed rapidly, the social environment has been stable and the laws and regulations system have perfected gradually. All these provided a stable and reliable social condition that is needed to conduct forest carbon-sink program, and directly enhanced the investors' willingness to invest. Moreover, the form of ownership of our country's large numbers of state-owned forest is comparatively uniformed, has less conflict to law about property right, it is favorable to achieve scale forestation and unified management. Compared to some small-scale forest carbon-sink programs, scale forestation can largely reduce the transaction cost that is generated during the design and conduction process of the forest carbon-sink program, and acquire economies of scale. Forestation and forest management belong to labor intensive industry, and China has abundant labor resources and the price of the labor is comparatively low. Therefore, China has strong competitiveness during the process to carry out the international forest carbon-sink program.

\section{2) China has abundant forest carbon-sink resource}

According to the data of the $7^{\text {th }}$ national forest resources inventory, by 2008, our country's forest area was 195 millionhm ${ }^{3}$, the percentage of forest cover was $20.36 \%$, achieved the target that the percentage of forest cover reach $20 \%$ by 2010 ahead of the schedule. In recent 30 years, 
China's new forestation area has increased gradually, forest stock volume has risen steadily, and the area of artificial forestation was at the top of the world. Furthermore, forest quality has been improved, age structure and forest type structure has got heartening changes, carbon reserve has shown an increasing trend, China has been qualified to develop forest carbon-sink transaction[5].

3) Domestic pilot transaction of forest carbon-sink has been proceeding

On $1^{\text {st }}$ Nov, 2011, the CGCF (China Green Carbon-Sink Foundation) and the Huadong Forestry Exchange met on the signing ceremony of the forestry carbon-sink transaction subscription held in Yiwu, Zhejiang province. Ten enterprises offered to buy the initial forestry carbon-sink target, 148 thousand ton at the price of 18 yuan per ton, and to acquire the transaction documents issued by Huadong Forestry Exchange. Furthermore, micro forest carbon-sink transactions has emerged in Beijng and Wenzhou, accumulated valuable practical experience for us.

\section{B Weakness analysis}

1) Forest carbon-sink program has plus externality in itself

Generally speaking, most of the environmental products have plus externality, which is also called external economic and can bring the third person economic benefits that are not reflected through price[6]. Forest carbon-sink has typical plus externality, and provide human social economic benefits that can hardly be evaluated by improving environment and climate[7]. However, the owner of forest and owner of part of the non-public-owned forests do not acquire surplus economic benefit. If the owner can not acquire corresponding ecological compensation by activities such as proceeding forestation, forest management, vegetation recovery, the forestation fund can not be ensured, and only the government can conduct the forest carbon-sink program, the market transaction would not have large opportunities to be conducted.

2) The sense of forest operation is comparatively old

Due to the weak resource awareness, the economy development has always been depending on a single factor, lacking the sense of capitalization management and operation to resources. Therefore, the superior resources and production elements could not be configured reasonably and turn the resource superiority to the economy superiority, restricting the development of the forest region to a large degree. All of these are very harmful to fully utilize the resource superiority in this region, attract foreign investors to invest forestation and conduct forest carbon-sink transactions.

\section{SWOT STRATEGY FOR CHINA TO DEVELOP FOREST CARBON-SINK MARKET TRANSACTION}

By the SWOT analysis above to develop forest carbon-sink transaction and combine it with the current condition of our country's forest carbon-sink transaction, the following countermeasure should be put forward:

a. To use the international experience for reference, establish mechanism and rule, accelerate the construction of the software and hardware, which are needed to develop forest carbon-sink transaction. The rule and procedure to conduct forestation and afforestation programs of CDM are relatively complicated, so many parts in our country are unqualified to carry it out. Therefore, we should learn and utilize the transaction method that the foreign countries used to develop carbon-sink program, integrate our own country and region's practical condition, and actively propel the carbon-sink pilot program, in order to transform the carbon-sink resource superiority into economic benefit as soon as possible. The government and relevant departments should strengthen the research of forest carbon-sink transaction's basic theory, make the forest carbon-sink's production standard, measurement standard and identification standard, consistent with the international standard, and establish rules and specific operation details of forest carbon-sink transaction mechanism. We should impel the operation of carbon-sink pilot, at the same time, conclude and summarize the problems, which appeared during the carbon-sink transaction practice, and their solutions, build relevant data ban and information exchange platform of carbon-sink, thus to form an information sharing mechanism. New carbon-sink transaction market or develop forest carbon-sink transaction at the exist resource exchange need to be established as soon as possible, in order to provide a transaction platform to both sides of the forest carbon-sink business.

b. By introducing governmental intervention mechanism to solve the externality problem, to give full play to the function of the create environment and make market policy. Externality cannot be covered by market mechanism, but must result in the distortion generated on the resource allocation of the market mechanism. Since forest carbon-sink has great positive externality, especially under the circumstance that the market price of the forest carbon-sink is low. Forestry operators should acquire the social compensation by participating forest carbon-sink programs. The specific compensation standard can be determined by the price difference of the social marginal income and individual marginal income of the forestry owners' existing output. In this way, the externality problem of the forest carbon-sink program can be solved, and more forestry operators would be attracted to join the forest carbon-sink program. The compensation for the program participants can be the vertical transfer payment by the local finance. Also, the ecological transfer payment fund can be established, the implementer of the forest carbon-sink program would be offset by the regions that acquired the ecological service. Moreover, local governments can mainly support the programs, which have great potential to increase carbon sink, on the basis of the condition to conduct CDM forestation and afforestation, comprehensively consider the superiorities and weaknesses of different regions. For example, to eliminate the tax during the CDM program conducted by the top enterprises, or to give them subsidy according to the ratio of the contract price of forest carbon-sink program. The intervention of the compensation policy can remove production insufficiency caused by the production externality, and promote the benign development 
of the forest carbon-sink program.

c. To strengthen the scientific research and train professionals of carbon-sink transaction. Systems and policies should be conducted by people, and the professionals are especially critical. Forest carbon-sink is a new multidisciplinary subject, which lies between forestry and economics, and need to be seriously researched, seize the trends of the international carbon-sink market in time, get ready in the policy, theory, professional and such aspects, in order to promote the development of our country's carbon-sink program. The research of the carbon-circulation and carbon-reserves of forest ecosystem, as well as the function of the carbon-sink needs to be carried out. Great effort to broadcast and popularize the relative knowledge of forest carbon-sink needs to be made. As a newly developing subject, the relative basic concept and essence of the forest carbon-sink had not been comprehended by people, and lots of theories, methods and policies are still being explored. Therefore, we should increase the power of publicity, let people know carbon-sink, pay attention to carbon-sink and participate in the relevant activities of carbon-sink, and make more and more people know the great significance of carbon-sink in relieving climate change and promoting the social sustainable development.

d. To accelerate the construction of the transaction platform andinnovate financial products. We need to encourage the intervention of the financial industry and refresh the carbon transaction market. It is an indispensable way for carbon transaction market, only by the abundant capital injection and circulation can keep the carbon transaction market active. China should take time to research some relevant policies and measures, encourage and lead domestic financial institutes to participate carbon transaction, perfect and standardize the management mechanism of the carbon finance, promote the financial industry and carbon transaction to develop together[8].

\section{REFERENCES}

[1] Han Zheying, System service and integrated research of forest tourism industry in Heilongjiang province, Doctoral Dissertation of Northeast Forestry University, 2007: 74-82

[2] Xu Jun, Mechanism, practice and inspiration of forest carbon-sink transaction in America, North China Financial, 2010, 9: 19-21

[3] Xu Shanshan, Research of the forest carbon-sink problems under CDM frame in Heilongjiang forestry industry area, Doctoral Dissertation of Northeast Agricultural University, 2010: 97-100

[4] Lin Derong, Marketization research of Forest carbon-sink services, Doctoral Dissertation of Chinese Academy of Forestry Sciences, 2005: $48-49$

[5] Fang Jingyun, Chen Ping, Dynamic Change and Its Significance of Chinese Forest Cover Carbon Stock, Chinese Bulletin of Botany , 2001, 43 (9): 967-973

[6] Tom Tietenberg, Yan Xuyang, Environmental and natural resource economics[M].Beijing: Economic Science Press, 2003.2.

[7] Li Jing, Thinking of the externality of forest carbon-sink, Academic Approach, 2011, 6: 378

[8] Jiang Feng, Liu Weimin, SWOT analysis of the construction of Chinese carbon transaction market, Environmental Production, 2009, 7: 78-79 